\title{
Rachel Jenkins
}

\author{
In conversation with Rosalind Ramsay
}

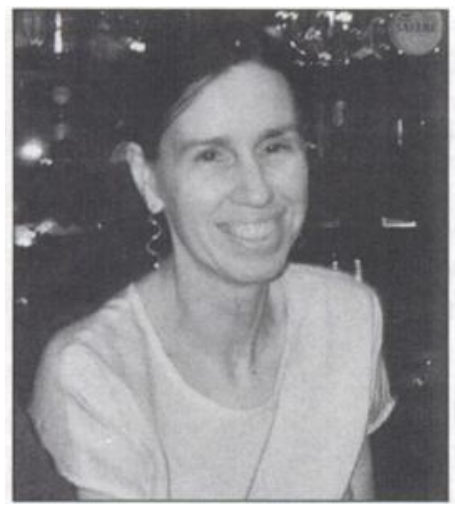

Rachel Jenktins
Dr Rachel Jenkins, bom 1949, was educated at Giton College. Cambridge and St George's Hospltal Medical School, London. She became an Honorary Sentor Lecturer at the institute of Psychiatry in 1982 and was Consultant and Senlor Lecturer at St Bartholomew's Hospltal Medical School from 1985-88. She became Pilncipal Medical Officer at the Department of Health in 1988. She is the author of approximately 80 publications on aspects of mental health, including the care of the elderly, sex differences in minor pyschlatilic morbldity, occupational psychiatry, outcome indicators, alcohol consumption, primary care of mental health and on the Health of the Nation.
For many psychiatrists the Department of Health must seem part of a rather unknown and probably very different world; the home of Ctvil Servants and policy makers, a source of statements and discussion papers. In addition to the many bureaucrats it also employs a number of doctors. Dr Rachel Jenkins, Principal Medical Officer in one of the medical branches of the Department of Health, leads a team of doctors working with four different administrattve divisions; on medical ethics, phsyical and sensory disablilty, the care of the elderly, as well as mental illness, learning disability and mentally disordered offenders.

Dr Ramsay interviewed Dr Jenkdns in June 1994.

What was it like being posted to a department in the ctull service?

Dr Jenkdns, relaxed and friendly, spoke with obvious enthusiasm about her work in the Department. "Coming in here gave me another perspective. Instead of my thinking being drtven by the next patient in the clinic or on the ward round I started to have a broader view of the NHS, taking more of a population perspective on meeting health needs, which I was able to integrate with my research background as an epidemiologist. In terms of practicalities, compared with the routine which ward rounds and clinics impose on the week, every day in the Department is different."

What's happened strce you've been in the department?

"I came at a time of great change. Over the six or seven years I've been here the Department has become a much more dynamic forwardlooking organisation. As it brought in more good people its stature in the eyes of the outside world has grown and good people have been more willing to come in. I would like to see working in the Department of Health as scientific, prestiglous, and influential as any of the top flight untversity departments in the country. And I am extremely fortunate in the high calibre of the psychiatrists working with me. In my post, I work in parallel with the assistant secretaries in each of the four administrattve branches to make sure they get the professional advice they require. In the old days the administrators used to run the Department completely, only taking professional advice as they felt like it. We're now trying much more to work in terms of 
equal partnerships between the medical and administrattve branches". Dr Jenkins and her branch also liaise with other government departments such as the Home Office, the Department of Education, the Department of Employment, the Health and Safety Executtve and the Department of the Environment.

\section{What do you feel you've achieved here?}

"A number of things, but team work is as much a part of everyday working in the Department of Health as it is in clinical practice, and it's hard to disentangle what is my input and what is everybody else's input. Everyone's helpful and collaborattve, and we're all doing this together."

Perhaps carving out mental Mness as one of the key areas in Health of the Nation?

"I see Health of the Nation as a significant opportunity for the development of mental health services. My main worry is that doctors and management will not grasp it sufficiently. The huge significance of the Health of the Nation is that it moves the NHS towards a focus on outcomes rather than processes, looking at real health gains rather than, for example, simply lengths of waiting lists or number of admissions. At last we've got mental health there as a real priority, with a clear framework for action. Besides emphasising the importance of specialist services for mental iliness, we've also been able to get other mental health issues more onto the agenda, such as the primary care of people with mental illness and mental health in the workplace. While policies for comprehenstve services in the community have been in place for a long time, purchasers have not all been buying the necessary infrastructure. At last mental illness services are becoming very much more up front in managers' minds. The various recent reports such as the Clunis Report, the House of Commons Select Committee Report and the Audit Commission Report all help to raise awareness of the issues and of what needs to be done to make local comprehenstve care work."

How do you cope with the constraints of limited resources?

"As in the rest of the NHS, resources will never match demand. Furst it is very important that we spend what we have got in the best way possible, targeting those most in need. We've evidence that this is not entirely the case at the moment, given the variation between different districts in their spending on mental health services. Planners need to look at their budgets in relation to decent assessments of need."

Dr Jenkins explained, "We must have a proper epidemiological assessment of need so planners can work out whom they have to cater for in an appropriate order of priority. The national psychiatric morbidity survey was a twinkle in my eye when I first came to the Department, and we have given it a lot of thought and planning, but now six years later it's nearly complete. We commissioned the Office of Population Censuses and Surveys to run the survey this year. There are four elements: a household survey, a survey of people in institutions, and supplementary samples of people with psychosis, and homeless people. We're looking at the prevalence and severity of mental illness and risk factors as well as the use of services and family burden. The survey is taking people from every postal district to give us a good national picture of mental health needs.

"The next step is for district planners to look at the whole range of mental illness in their own districts. Directors of public health will be able to use the data from the national psychiatric morbidity survey, and will also be able to use its methodology to say, We've got this range of patients (some people need medium secure faclitiles, others need community asylum, or day places or hostel places, some need an intense care programme approach, others a minimalist care programme approach, some only need basic care that can be provided by nonspectalists), going from the most severe to the most minor mental illnesses, and also we've got this range of resources'. We need to target our specialists on the most severely 111 group while supporting and educating general practitioners to deal with routine depression and anxiety within the primary care team."

To make her point even clearer Dr Jenkins jotted down some figures. "If there is one community mental health nurse to every five GPs and every GP has a list size of about 2000 patients, including seven with chronic severe mental illness, this would give community mental health nurses a case-load of 35 such patients, which is already a large number. But each GP also has around 300 patients with 
depression and anxdety. Supposing a GP was very restrained and only referred three or four of these people to the community mental health nurse, even this number will wreck the community mental health nurse's case load and at the same time it'll make little impact on the care of the remaining 297 patients with minor psychiatric illness. We've got to target specialists at the group of patients with the more severe mental illness, and primary care at the other group. I'd like to see a very clear interface with good criteria for referral for each of the main diagnostic groups between primary care and specialist care. Of course many cases of depression and other neuroses can be extremely severe and difficult to treat, and it is certainly appropriate to refer these for spectalist care. However, the majority are relattvely straightforward to manage and this can be most appropriately and cost effectively done in primary care."

\section{How will you achieve your viston in practice?}

"I think we can try and get at it from both top down and bottom up. Top down managers are giving out messages down their managerlal networks to target, target, target so that specialists concentrate on seeing the really difflcult people and doing that well, and also take a role in supporting the primary care team in managing the minor llinesses. We also need to target community mental health nurses better. We know from the third quinquennial community psychiatric nurse survey that in the past too many community mental health nurses have been concentrating on minor llinesses to such an extent that three-quarters of psychotic patients did not have a community mental health nurse.

"Bottom up we need to train and support members of the primary care team to manage the minor lllnesses. At present even among the younger GPs only around $45 \%$ have done psychiatry as part of their vocational training, but they are the gate keepers to secondary care and they need appropriate education in assessing and diagnosing common forms of psychiatric lliness with appropriate criterla for referral to spectalist care. A common misconception in general practice is that regular depots for people with chronic schizophrenia are all that is required. GPs have told me that they are retrieving many of their patients with severe mental illness from the speclalist services, in order to reduce their expenditure purchasing secondary care. But of course, giving depots is only the beginning. People with severe mental illness also need relevant social and psychological care, planned, coordinated and regularly reviewed. Another important issue to tackle in primary care relates to the high mortality among people with severe mental illness from physical disease.

"We are piloting different models of good practice in the primary care of mental health. for example, evaluating the use of a GP facilitator to help practices improve and systematise their methods of assessment, diagnosis, management and criterla for referral to specialist care, and evaluating the use of primary care nurses to enable a sensible division of labour within the practice.

"We have appointed a senior GP fellow to take a national lead in educating the nation's GPs about mental health issues in primary care. This is Dr Andre Tylee, senior lecturer in general practice at St George's Hospital, and he is using a cascade approach to teach the teachers (GP tutors, course organisers etc) about mental health in primary care."

How does this scheme relate to the World Health Organization's goal of integrating mental health with primary care?

"WHO is quite right to keep saying that $90 \%$ of mental illness is seen in primary care. I think WHO has done a wonderful job flagging up the importance of the primary care of mental illness. Getting the approprlate balance between primary and specialist care depends on the individual country concerned and the resources it has available. The public health impact of mental illness is huge. Mental illness is a leading cause of disability, or DALYs, disability adjusted life years".

"The Department of Health maintains contact with WHO, exchanging ideas and working on joint projects. Recently WHO has been interested in our work on health care indicators, Health of the Nation and the prevention of suicide. We liaise with WHO in Geneva, and with the European Office in Copenhagen".

Psychiatry in the workplace is another area of interest you mentioned

"This flags up many of the same issues as mental health in primary care. The prevalence of psychiatric illness in the workplace is very high. It often remains undetected even though 
there are huge consequences for Indtviduals and their families and also for their workplaces with economic costs in terms of sickness leave, labour turnover and decreased productivity. Ten years ago employers didn't like to talk about mental health in the workplace but now it is regarded as a serious issue. Historically employers have been rather more willing to look at other areas such as alcohol and drugs, even AIDS, before tackling mental illness, but I think mental illness has more costly consequences than those topics for the workplace. One of the things I would like to see happening is for employers to take a more systematic approach to mental illness based on the public health framework of primary, secondary and tertiary prevention.

"At the primary prevention level we already have a lot of research about what is stressful in the workplace, and reducing workplace stressors is in general totally in keeping with current knowledge on good people management. There is also research on providing counsellors through employment assistance programmes. These allow employees to access a counsellor in a confldentlal way about any concerns they have at work or at home. At the secondary prevention level we need line managers and colleagues to be aware when others at work are not coping, and to have systems in place so that help can be obtained quickly, if necessary through occupational health departments or GPs. At the tertiary prevention level, thinking about rehabilitation, a lot of people are retired on medical grounds who perhaps should not have been, but at the time no effort was put into supporting them and getting them back to work.

"It is particularly important to be aware that the NHS is the largest employer in the country and certainly doctors don't always take good care of themselves, but I think attitudes here are starting to change. We've got within the Health of the Nation one sub-committee which is about the health of the NHS work force. More specifically about mental health, we've produced a guide for employers about mental health in the workplace and we've sent a copy to every NHS manager, as well as to other large employers in the country. Here at the Department of Health we're trying to put our own house in order and have developed our own mental health policy for DH staff. We are also approaching the problem from a research angle and I'm pleased Professor Peckham has included it as one of the six national priorities for research on mental illness."
Can you tell me something more about yourself and beting a doctor?

"Being a doctor is such a consuming activity it takes over your whole life and I recognise there have been costs to me personally through being so busy. As a student I enjoyed hospital medicine and following a student research job in Tanzania, I considered specialising in tropical diseases, but after marrying, decided to train as a GP. As training schemes were then in their infancy, I decided to plan my own scheme, and knowing that psychiatry would be useful I applied for a job at the Maudsley Hospital. Of course, once there, I became hooked and decided to stay in psychiatry. That was my ostensible pathway to a career in psychiatry but now, looking back, even when I was a student at Cambridge doing the preclinical course, I was already reading R. D. Laing and Szasz and as a sixth former I had attended a talk at the Royal Institution by William Sargant on 'Battle for the Mind'. It is interesting to acknowledge that these people were very influential in stimulating me and my contemporaries at untversity, even though I would not remotely agree with them now".

What about role models, people who have influenced you in the way you work?

"Michael Shepherd was a mentor for many years at the Institute of Psychiatry, Tony Clare at Barts where I moved to be a consultant and senior lecturer and at the Department of Health, John Reed. Other key people are Anthony Mann as a research collaborator and looking further afield Norman Sartorius at WHO."

\section{But these are all men.}

"Well there is also my mother who has been a great role model for me as a working mother with a vision. Thinking of parents, I have recently realised that my first experience of epidemiological techniques was with my father assisting him in ornithological surveys for the British Trust for Ornithology, to document whether bird populations were falling in response to increasing use of pesticides in farm landl (I grew up in a rural part of Herefordshire-and this, of course, may explain why I am particularly concerned about the high suicide rate among farmers. Whenever I talk to friends in Herefordshtre, everyone knows someone who has kdlled himself)." 
Dr Jenkins remains committed to her vision for mental health services but returned to her feelings of uncertainty about the personal costs to herself, "In many ways I don't want my children to be doctors, and if anything I would put them off the idea. I would like them to have a more balanced life, to have plenty of time for other things.

"My time to relax is really only when I am on holiday and then I enjoy botany and bird watching. reading and walking as well as spending more intenstve time with my children. Yesterday I was reading a book by Git Mehta on the plane about a retired ctvil servant living on the banks of a sacred river in India and describing the life stories of people who pass by...W Wld Swans is another book which has had an enormous impact on me this year, particularly as I was fortunate in being able to visit China last March, so I read it on the plane going out."

\section{And your future?}

"I don't think I will stay in the Department of Health until I am 60 but at the moment I think it is important that we capitalise on the head of steam there is here working with a Secretary of State who is so committed to improving mental health care so that we can push things as far as possible. When I leave I want it to be in a planned way. Perhaps I have missed out on the academic side of my career but I hope there will be time to catch up later."

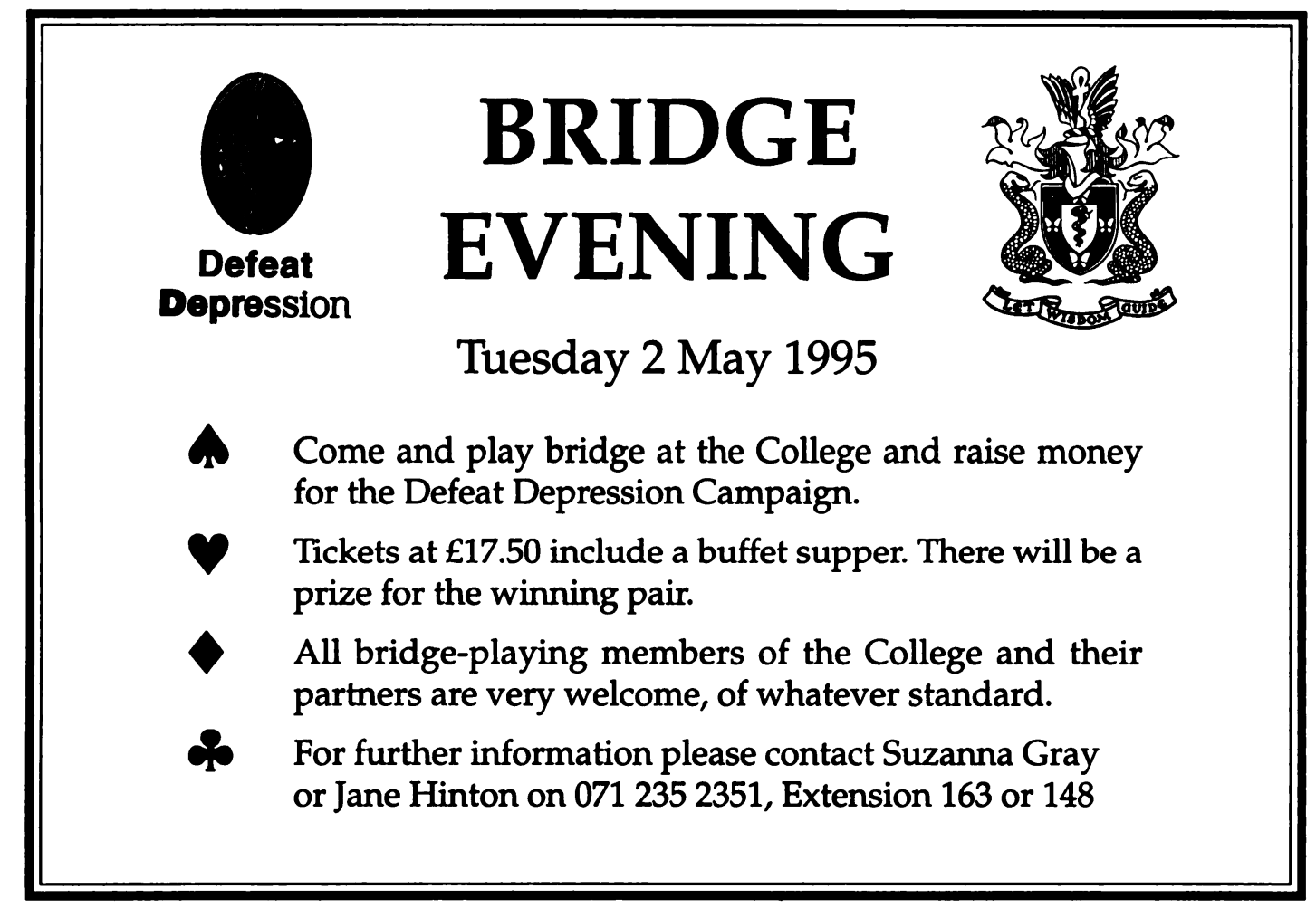

